\title{
Eletro-oxidação de glicerol sobre catalisadores de Pt modificados por Ge
}

\author{
Victor Secco Lemos, Antônio Morino, Prof. Dr. Pablo S. Fernández*
}

\section{Resumo}

O biodiesel é um combustível renovável que cresce em demanda anualmente, principalmente no Brasil, e um subproduto da sua produção é o glicerol, obtido a uma taxa de $10 \%$ em peso. O glicerol é um composto com vários usos comerciais, mas que tem um grande excedente de oferta que pode ser utilizado em muitas outras rotas, uma delas sendo em eletrolisadores para obtenção de produtos com alto valor agregado, ou em células a combustível para produção de energia elétrica. Nesse contexto, o objetivo deste projeto de iniciação científica é investigar o efeito da modificação de $\mathrm{Pt}$ com adátomos de Ge para a eletro-oxidação do glicerol em meio alcalino. A atividade desse catalisador será investigada utilizando uma célula eletroquímica convencional com um eletrodo de Pt policristalino, seguido de estudo da seletividade e mecanismo de reação com FTIR in situ e HPLC.

\section{Palavras-chave:}

glicerol, eletro-oxidação, adátomos.

\section{Introdução}

O uso de combustíveis renováveis é um assunto cada vez mais relevante. Devido a isso, muitas fontes de energia renovável estão sendo estudadas, como a eólica, geotérmica, e biomassa, essa última sendo um tópico de interesse em muitas partes do mundo. A biomassa é usada na produção de biocombustíveis como etanol, biodiesel e biogas $^{2}$. O biodiesel é produzido com o glicerol ( $\mathrm{GlOH})$, que é um co-produto da síntese, em $10 \%$ em massa do produto. ${ }^{3}$ Nos últimos anos houve um aumento na produção de biodiesel, tornando o $\mathrm{GIOH}$ mais barato. Este, devido à quantidade de produtos ao qual pode ser oxidado, é uma molécula de muito interesse sintético. ${ }^{2} \mathrm{Um}$ dos métodos de síntese é a eletro-oxidação do glicerol (GEOR), fruto da valorização do $\mathrm{GlOH}$ por rota eletroquímica. Anteriormente, já foi investigada a GEOR, em meio ácido, com a adição reversível e irreversível de adátomos ( $\mathrm{Sn}, \mathrm{Pb}, \mathrm{Sb}$ e In), que apresentou resultados positivos para $\mathrm{Sb}$ e $\mathrm{Bi}^{4,5}$ Nesse contexto pretendemos estudar a modificação do eletrodo de Pt com adátomos de Ge, ainda não estudados pelos grupos de eletroquímica.

\section{Resultados e Discussão}

Realizamos a voltametria cíclica em meio ácido (figura 1) para verificar a limpeza do sistema e do eletrodo.

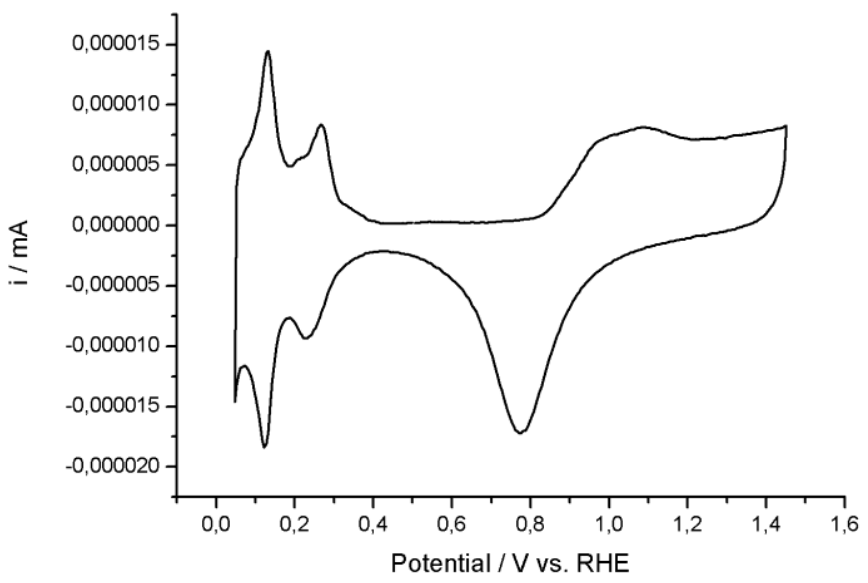

Figura 1. Voltametria cíclica de Pt em meio de $\mathrm{H}_{2} \mathrm{SO}_{4}$ $0,5 \mathrm{M}$.
Em seguida realizamos a oxidação do $\mathrm{GIOH}$ com diferentes concentrações do metal a ser depositado no eletrólito (figura 2) em meio básico, no qual a Pt apresenta maior atividade.

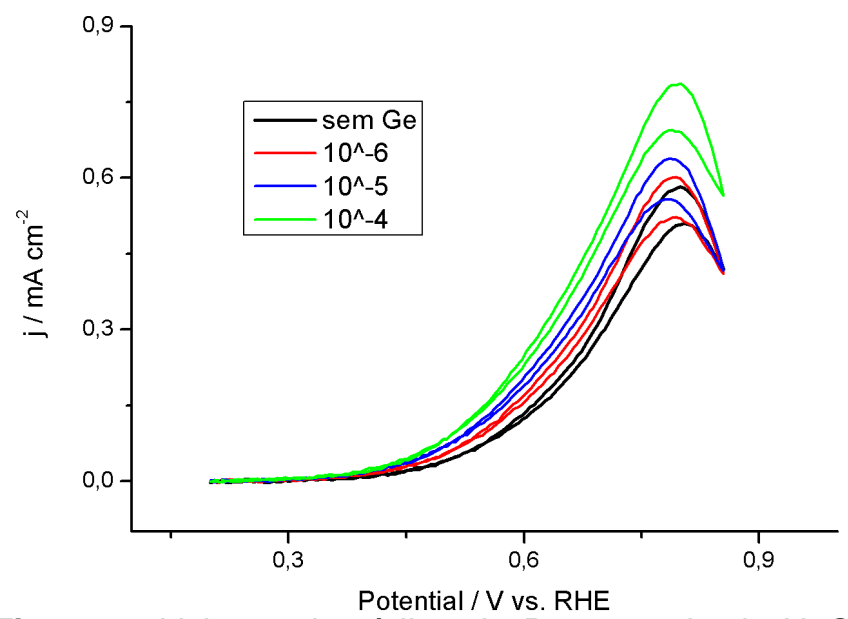

Figura 2. Voltametria cíclica de $\mathrm{Pt}$ em meio de $\mathrm{NaOH}$ $0,1 \mathrm{M}$ e $\mathrm{GIOH} 0,1 \mathrm{M}$ na presença de $\mathrm{GeO} 2$ em diferentes concentrações a $0,05 \mathrm{Vs}^{-1}$.

\section{Conclusões}

Verificando a densidade de corrente na oxidação, podemos ver que há um aumento na atividade do eletrodo com o aumento da concentração de $\mathrm{Ge}$ na solução. Nossos próximos passos serão realizar experimentos para concentrações maiores e testar a reprodutibilidade.

1. D. Larcher, J.M. Tarascon. Nat. Chem. 7 (2015) 19-29

2. Katryniok, B.; Kimura, H.; Skrzyńska, E.; Girardon, J.-S.; Fongarland, P.; Capron, M.; Ducoulombier, R.; Mimura, N.; Paul, S.; Dumeignil, F. Green Chem. 2011, 13 (8), 1960.

3. Ciriminna, R.; Pina, C. Della; Rossi, M.; Pagliaro, M. Understanding the Glycerol Market. Eur. J. Lipid Sci. Technol. 2014, 116 (10), 1432-1439

4. M. B. C. de Souza, R. A. Vicente, V. Y. Yukuhiro, C T. G. V. M. T. Pires, W. Cheuquepán, J. L. Bott-Neto, J. Solla-Gullon, and P. S. Fernandez., ACS Catal., 2019.

5. Kwon, Y.; Hersbach, T. J. P.; Koper, M. T. M. Top. Catal. 2014, 57 (14-16), $1272-1276$ 